\title{
Metacognitive processes \\ and qualities as determinants \\ of general manage-ment styles
}

\section{A. A. Karpov ${ }^{1}$}

${ }^{1}$ P. G. Demidov Yaroslavl State University, 14 Sovetskaya str., Yaroslavl 150003,

Russian Federation

DOI: $10.18255 / 1996-5648-2021-4-582-591$

Research article

Full text in Russian

The article presents theoretical and empirical materials that reveal the specifics of the main parameters of the metacognitive sphere of personality as determinants of general management styles. It is shown that one of the most constructive means of such disclosure is to identify the relationship between management styles as one of the central constructs of management psychology, on the one hand, and the main metacognitive parameters (procedural, strategic and other characteristics), on the other. The regularities of the influence of metacognitive factors on the main general management styles are established. It is shown that they are characterized by different values of the indexes of integration (coherence), differentiation (divergence) and the index of general organization of the metacognitive sphere. The provisions are formulated according to which general management styles have a structural, rather than analytical determination in relation to those metacognitive factors on the basis of which they are formed.

Keywords: metacognitive sphere of personality; management activity; metasystem approach; management style; structural organization; indexes of structural or-ganization

\section{INFORMATION ABOUT AUTHORS}

Karpov, Alexandr A. | E-mail: karpov.sander2016@yandex.ru Doc. Sc. (Psychology), Associate Professor

Funding: RFBR, project 19-013-0013. 


\title{
Метакогнитивные процессы \\ и качества как детерминанты \\ общеуправленческих стилей
}

\author{
A. А. Карпов ${ }^{1}$
}

${ }^{1}$ Ярославский государственный университет им. П. Г. Демидова, ул. Советская, 14, Ярославль, 150003, Российская Федерация

DOI: $10.18255 / 1996-5648-2021-4-582-591$

УДК 159.9

Научная статья

Полный текст на русском языке

В статье представлены теоретические и эмпирические материалы, раскрывающие специфику основных параметров метакогнитивной сферы личности как детерминант общеуправленческих стилей. Показано, что одним из наиболее конструктивных средств такого раскрытия является выявление взаимосвязи стилей руководства как одного из центральных конструктов психологии менеджмента, с одной стороны, и основных метакогнитивных параметров (процессуальных, стратегиальных и иных характеристик) - с другой. Установлены закономерности влияния фракторов метакогнитивного плана на основные общеуправленческие стили. Показано, что они характеризуются различными значениями индексов интегрированности (когерентности), диффреренцированности (дивергентности) и индекса общей организованности метакогнитивной сферы. Сфрормулированы положения, согласно которым общеуправленческие стили имеют собственно структурную, а не аналитическую детерминацию в отношении тех метакогнитивных фракторов, на основе которых они фрормируются.

Ключевые слова: метакогнитивная сфрера личности; управленческая деятельность; метасистемный подход; стиль управления; структурная организация; индексы структурной организации

\section{ИНФОРМАЦИЯ ОБ АВТОРАХ}

Карпов, Александр Анатольевич $\mid$ E-mail: karpov.sander2016@yandex.ru

Доктор психологических наук, доцент

Финансирование: РФФИ, проект № 19-013-0013. 
Карпов А. А.

\section{Постановка проблемы исследования}

Среди многообразия сложившихся $\kappa$ настоящему моменту и интенсивно развивающихся направлений современной психологии ведущее положение занимают психологическая теория деятельности [1-5], с одной стороны, и метакогнитивизм [2, 5, 6-10], с другой. Во-первых, подобная их роль обусловлена рядом новых тенденций, свойственных психологии труда и смежным с ней дисциплинам (организационной и индустриальной психологии, психологического анализа деятельности, психологии управления и др.) на данном этапе их развития [11]. Главная из них -стремление к интеграции теоретических представлений и результатов прикладных исследований и формирование на этой основе возможной единой психологической отрасли. Во-вторых, и психологическая теория деятельности, и метакогнитивизм (и шире - метакогнитивная психология), характеризуясь высоким уровнем и темпами развития, во многом определяют и важнейшие тенденции развития психологического знания. Однако до сих пор они разрабатываются подчеркнуто автономно друг от друга, что обусловливает множество принципиальных трудностей и проблем, попытка решения которых была предпринята нами в цикле предыдущих работ $[2,5]$. Принципиально важно отметить, что в этих исследованиях по отношению к рассматриваемой проблеме был реализован метасистемный подход. Именно такой общий методологический подход наиболее релевантен природе и содержанию метакогнитивной сферы личности, что было показано, в частности, в работе [2], направленной на установление закономерностей метакогнитивной регуляции деятельности управленческого типа. Наряду с этим, важно отметить, что одно из наиболее традиционных и широко представленных в психологии управления направлений -исследование стилей руководства и лидерства, а также проблема принятия решений. Обе категории фрактически определяют все содержательные и процессуальные характеристики управленческой деятельности, являются, по существу, системообразующими по отношению к ней. $К$ настоящему времени сложился целый ряд различных концептуальных подходов к разработке классификаций стилей руководства, стилей принятия управленческих решений и др., что предоставляет возможность разработки комплексных научно-исследовательских процедур. В связи с этим одним из основных этапов реализации общего цикла исследований, направленного на выявление и объяснение закономерностей, имеющих место во взаимосвязи метакогнитивной сферы личности как регулятора управленческой деятельности и самой этой деятельности, выступает изучение стилевых особенностей ее реализации, возникающих под де- 
терминирующим воздействием фракторов метакогнитивного плана. Следует учитывать, что само понятие индивидуально-стилевых различий, как правило, специфицируется до понятия общеуправленческих стилей (или стилей руководства), в результате чего обычно выделяются три «классических» стиля (авторитарный, демократический или коллегиальный и попустительский).

\section{Организация процедуры и методы исследования}

В исследовании было использовано шесть психодиагностических методик опросного типа: методика «Метакогнитивной включенности в деятельность» (Metacognitive Awareness Inventory - MAI) [7-8]; методика диагностики рефлексивности (А. В. Карпов, В. В. Пономарева), включающая субшкалы определения ретроспективной рефлексивности, рефлексии настоящего, рефлексии будущего, а также интегральную оценку развития рефлексивности $[4,8]$; методика определения уровня выраженности и направленности рефлексии М. Гранта, включающая субшкалы диагностики ауторефлексии и социорефлексии (по [6-8]); методика Д. Эверсон на диагностику меры и характера метакогнитивного мониторинга (по [6-8]); опросник степени выраженности средств антирефлексивной направленности (А. А. Карпов [5]); методика определения индивидуальной степени выраженности процессов метамышления (А. А. Карпов [5]); методика определения стиля руководства трудовым коллективом (В. П. Захарова и А. Л. Ж⿱㇒рравлева) [12-13].

Помимо этого, в исследовании был реализован отдельный блок методов математико-статистической обработки и интерпретации данных, включавший в себя коэффициент ранговой корреляции Спирмена (@), метод вычисления матриц интеркорреляций, метод определения индексов структурной организации, метод экспресс- 2 , а также Н-критерий Краскела-Уоллиса.

В проведенном исследовании приняли участие люди, занимающие руководящие должности в организациях и принадлежащие к среднему и высшему звеньям управления. Общая выборка составила 200 человек. Первый этап исследования состоял в том, что в пределах данной выборки руководителей была проведена методика определения стиля руководства трудовым коллективом (В. П. Захарова и А. Л. Журавлева). По результатам этой психометрической процедуры вся выборка была дифференцирована по признаку принадлежности к тому или иному общеуправленческому стилю. Далее каждый испытуемый выполнил задания методик на диагностику уровня выраженности основных параметров метакогнитивной сферы личности. 


\section{Результаты исследования и их обсуждение}

Вначале следует особо отметить, что в процедурном отношении исследование предполагало два отдельных, однако взаимосвязанных друг с другом этапа. Первый из них, традиционно обозначающийся как аналитический, заключался в установлении различий между исследуемыми группами испытуемых - руководителей, принадлежащих к трем общеуправленческим стилям. В этом случае нами был применен непараметрический Н-критерий Краскела-Уоллиса. По результатам его реализации можно констатировать, что различия между совокупностью результативных показателей по всем используемым в исследовании методикам оказались статистически значимы. Это означает, что на аналитическом уровне изучения метакогнитивных параметров в трех отдельных группах испытуемых-руководителей имеет место специфическая, присущая исключительно каждой из групп характеристики мера выраженности метакогнитивных процессов, качеств, стратегиальных и иных характеристик. Этот полученный результат, как мы полагаем, оказывается вполне достаточным для констатации положительного ответа о том, что метакогнитивная сфера личности у руководителей, принадлежащих к разным общеуправленческим стилям, закономерным образом претерпевает определенные и вполне очевидные особенности при сопоставлении исследуемых показателей друг с другом. Вообще, было бы не вполне логично априорно предполагать, что разные стили будут обнаруживать одинаковые характеристики. И это даже относится не только, а возможно, и не столько к метакогнитивным процессам, хотя, как показали полученные на аналитическом этапе результаты, и к ним тоже и в очень очевидной мере.

Наряду с этим, как показывает практика выполнения целого ряда схожих исследовательских процедур, аналитический этап в изучении того или иного предмета может и должен быть дополнен другим структурным, который предоставляет возможности получения относительно более точных результатов и позволяет установить более широкую совокупность закономерностей. Он же в данном случае является наиболее адекватным природе изучаемого предмета - метакогнитивной сферы личности в управленческой деятельности. Вместе с тем зачастую имеет место очевидное несоответствие полученных на аналитическом и на структурном уровнях результатов. Вторые оказываются отличными от первых. Это, однако, не «ослабляет» общий потенциал математико-статистических критериев, а, напротив, усиливает возможности и собственно “разрешающую способность» метода структурно-психологического анализа. 
Таким образом, на основании уже полученных после проведения методик результатов был реализован уже не аналитический, как в предыдущем случае, а структурный уровень исследования взаимосвязи стиля руководства и структурной организации основных параметров метакогнитивной сферы личности руководителей. Каждая из матриц вычислялась отдельно для трех групп респондентов (основание для дифреренциации - общеуправленческий стиль деятельности). Были построены структурограммы метакогнитивных характеристик в каждой группе, отражающие их общую структурную организованность, а также наличие между ними значимых взаимосвязей. Далее по результатам определения данных матриц были подсчитаны индексы когерентности, дивергентности и организованности структур метакогнитивных параметров (ИКС, ИДС и ИОС). Индекс когерентности структуры параметров (ИКС) определяется как фрункция числа положительных значимых связей в структуре и степени их значимости; индекс дивергентности структуры (ИДС) - как функция числа и значимости отрицательных связей в структуре; индекс организованности структуры (ИОС) - как фрунцця соотношения общего количества положительных и отрицательных связей, а также их значимости. При этом учитываются связи, значимые при $\alpha=0,01$ и $\alpha=0,05$; первым приписывается "весовой» коэффициент 3 балла, вторым - 2 балла. В ряде случаев учитываются и связи на $\alpha=0,10$ (с «весовым» коэфорициентом 1 балл) [2].

Таблица 1

\section{Сводная таблица индексов структурной организации}

\begin{tabular}{|c|c|c|c|}
\hline \multirow{2}{*}{ Индексы } & \multicolumn{3}{|c|}{ Стиль } \\
\cline { 2 - 4 } & Коллегиальный & Директивный & Попустительский \\
\hline ИКС & 52 & 27 & 8 \\
\hline ИДС & 6 & 0 & 3 \\
\hline ИОС & 46 & 27 & 5 \\
\hline
\end{tabular}

Из таблицы 1 видно, что исследуемые общеуправленческие стили значимо различаются по всем трем структурным индексам. Так, индекс когерентности и индекс общей организованности у руководителей коллегиального стиля значительно выше, чем у представителей директивного и попустительского стилей, что свидетельствует о более высокой степени структурной организации метакогнитивной сферы у испытуемых-руководителей данной группы. Подобные результаты можно 
объяснить, по нашему мнению, следующим образом: возможно, для таких руководителей наиболее эфрфективной является в различных сфеpax управленческой деятельности (коммуникативная, принятие решений и т. д.) гармоничная, структурированная представленность основных компонентов метакогнитивной сферы личности и, главным образом, высокая и выше среднего выраженность основных метакогнитивных характеристик в контексте единоличного принятия решений и принятия ответственности. Более того, сам по себе коллегиальный стиль предполагает опору на конструктивную межличностную коммуникацию, что, как мы полагаем, в существенной степени способствует усилению роли социорефлексии, метакоммуникативных процессов, повышению общего метакогнитивного потенциала структуры за счет возникновения между отдельными метакогнитивными качествами отношений синергетического типа. Кроме этого, нельзя не отметить и очевидное содержательное и даже этимологическое сходство коллегиальности принятия управленческих решений и метакогнитивных параметров. И то и другое суть категории объединяющего - синтезирующего плана. И если первое - в отношении общности и учета мнений сотрудников, то второе - относительно интегративного единства образований психического плана. Как указывается в [14], «все основные процессы и образования психики обладают очень общей и фактически фундаментальной особенностью - свойством функциональной обратимости. Они могут реализовывать свой функциональный потенциал в отношении самих же себя и тем самым подвергаться своеобразному “удвоению”». В этой связи хорошо известно, что, наряду с «первичными» (познавательными) психическими процессами, существуют и "вторичные» - метакогнитивные, которые регулируют характер и форму проявления первых. Отсюда, полагаем, проистекают и высокие интегративные возможности метакогнитивной сферы у представителей коллегиального стиля управления. Кстати говоря, эти же результаты были получены нами ранее, например в [2-3].

Директивный стиль, напротив, предполагает скорее эффективное использование отдельных - частных - метакогнитивных параметров, а не их определенным образом организованной совокупности. Иными словами, имеет место скорее аналитическая, нежели структурная, детерминация. Вместе с тем нельзя не отметить и очевидно высокую роль директивного стиля в управленческой деятельности. Мера структурной организации основных метакогнитивных параметров в этом случае хотя и уступает в количественном отношении коллегиальному стилю, но имеет объективно высокие показатели. 
И наконец, отдельного внимания, полагаем, заслуживают показатели ИКС и ИОС в группе с попустительским стилем управления. Различия в структурной организации метакогнитивных параметров между стилями обусловлены содержательными особенностяли данных стилей в контексте реализации управленческой деятельности. Именно характеристики стиля выступают в роли факторов организации метакогнитивной сферы личности управленцев. Известно, что попустительский стиль предполагает, с одной стороны, «максимум» демократии» или же «видимость демократии» (исполнители могут высказывать свои позиции, но реального учета, согласования позиций не стремятся достичь), а с другой - «минимум контроля» (даже принятые решения не выполняются, контроль за их реализацией практически отсутствует, все «пускается на самотек»). В силу этих причин закономерным образом возникает вопрос о необходимости в организованности метакогнитивных и других характеристик в принципе. Очевидное ослабление их роли не может не отразиться и на тенденциях в архитектонике структуры метакогнитивных параметров. Она дезинтегрируется, уменьшается число значимых положительных связей. Вместе с тем это происходит не потому, что руководители «не могут», скажем, эффективно применять те или иные метакогнитивные стратегии, а потому, что скорее «не хотят» этого делать, хотя вполне возможно, что такой потенциал у них имеется, однако стиль управления не требует его раскрытия.

Рассмотрим показатели индекса дивергентности (ИДС) в каждой из трех исследуемых структур. Его значение во всех случаях оказалось очень малым. Подобный результат является закономерным. Дело в том, что сама природа метакогнитивных процессов и качеств предполагает усиление ресурсных возможностей психики, ее интегративных механизмов. По этой причине можно утверждать, что именно метакогнитивные параметры выступают в качестве действенных и конструктивных средств реализации управленческой деятельности.

Заключительным этапом эмпирического исследования является реализация метода $\chi 2$ в своем экспресс-варианте. Согласно содержанию данного метода ранжируются структурные веса всех элементов структур (трех групп). После присвоения рангов проводится корреляционный анализ каждой из структур друг с другом [2]. Таким образом, в случае получения значимых корреляций между группами испытуемых можно говорить лишь о количественных различиях между структурами и, наоборот, в случае выявления незначимых корреляционных связей следует утверждать, что различия между исследуемыми структурами качественны. Как известно, критическим значением выборочного коэффициента кор- 
реляции для трех коррелируемых параметров (по В. Ю. Урбаху) является 0,72 [15]. В нашем случае в результате реализации данного метода были получены следующие результаты. Структуры метакогнитивных параметров испытуемых, принадлежащих к трем исследуемым группам руководителей, при их сопоставлении друг с другом (посредством вычисления коэффициента ранговой корреляции Спирмена) оказались гетерогенными. Иными словами, это принципиально разные структуры. Можно предположить, что этот результат является вполне закономерным, поскольку отражает разнообразие в организации метакогнитивного потенциала в зависимости от принадлежности к тому или иному общеуправленческому стилю.

\section{Выводы}

1. По результатам исследования установлено, что стили руководства имеют структурную, а не аналитическую детерминацию относительно тех метакогнитивных факторов, на основе которых они формируются.

2. Основные общеуправленческие стили значимо различаются по всем трем структурным индексам, что обусловлено характеристиками организации метакогнитивных параметров в подгруппах руководителей, дифференцированных на основании стиля деятельности.

3. Различия в структурной организации уровня выраженности параметров метакогнитивной сферы личности между стилями обусловлены их содержательными особенностями в контексте реализации управленческой деятельности.

4. Обнаруженные изменения в структурной организации основных параметров метакогнитивной сфреры личности в разных подгруппах руководителей носят качественный, а не количественный характер, что свидетельствует о различиях в метакогнитивном потенциале в зависимости от принадлежности к определенному общеуправленческому стилю.

\section{Ссылки}

1. Карпов А. В. Психология деятельности: в 5 т. М.: Издательский дом РАО, 2015.

2. Карпов А. А. Структура метакогнитивной регуляции управленческой деятельности. Ярославль: ЯрГУ, 2018. 784 с.

3. Карпов А. В., Карпов А. А., Маркова Е. В. Психология принятия решения в управленческой деятельности. Метасистемный подход. Ярославль: ЯрГУ; М.: Издательский дом РАО, 2016. 644 с.

4. Карпов А. В., Пономарева В. В. Психология рефлексивных механизмов управления. М.: Институт психологии РАН, 2000. 283 с. 
5. Карпов А. А. Новые методики исследования метакогнитивной регуляции управленческой деятельности: учебное пособие. М.: МПСУ, 2019. 115 с.

6. Карпов А. А. Феноменология и диагностика метакогнитивной сореры личности. Ярославль: ЯрГУ, 2016. 208 с.

7. Карпов А. А., Карпов А. В. Введение в метакогнитивную психологию: учебное пособие. М.: МПСУ, 2015. 512 с.

8. Карпов А. В., Скитяева И. М. Психология метакогнитивных процессов личности. М.: ИП РАН, 2005. 325 с.

9. Metcalfe J. Evolution of metacognition / Handbook of Metamemory and Memory. New York: Psychology Press, 2008. P. 29-46.Metcalfe J. Evolution of metacognition. In J. Dunlosky, R. Bjork (Eds.), Handbook of Metamemory and Memory. New York: Psychology Press, 2008. P. 29-46.

10. Perfect T., Schwartz B. L. Applied Metacognition. Cambridge: Cambridge University Press, 2002. 220 p.

11. Карпов А. А. Современная организационная психология. М.: МПСУ, 2018. 256 c.

12. Ж Жравлев А. Л. Психология управленческого взаимодействия. М.: ИП РАН, 2004. 474 c.

13. Козлов В. В., Мазилов В. А., Фетискин Н. П. Социально-психологическая диагностика развития личности и малых групп: учебное пособие (2-е изд., доп. и перераб.). М.: МАПН; Изд-во Института психотерапии, 2018. 716 с.

14. Карпов А. А. Особенности структурно-фрункциональной организации метакогнитивной сфреры личности в управленческой деятельности // Ярославский психологический вестник. 2019. Вып. 2 (44). M; Ярославль: Титул. С. 64-69.

15. Суходольский Г. В. Основы математической статистики для психологов: учебник. СПб.: Изд-во СПбГУ, 1998. 464 с. 